\title{
A HISTÓRIA DO ENSINO DA FILOSOFIA NO SISTEMA ESCOLAR FRANCÊS E BRASILEIRO
}

\author{
DOI: http://dx.doi.org/10.1590/2236-3459/75689
}

\author{
Daniela Nienkötter Sardál \\ 'Universidade de São Paulo (USP), São Paulo/SP, Brasil
}

$\cos 80$

\begin{abstract}
Resumo
O presente artigo tem como objeto a história do ensino da filosofia no sistema escolar francês e brasileiro. Nosso objetivo é mostrar que, na França, onde o ensino da filosofia está presente nos currículos escolares há séculos, sua importância foi questionada apenas algumas vezes ao longo da história; ou seja, sua história é marcada por uma estabilidade. Por outro lado, verificou-se que no Brasil o ensino da filosofia é marcado por uma instabilidade. Chegamos a essa conclusão graças a uma análise comparativa de discursos, cuja questão de pesquisa concerniu às representações sociais acerca da filosofia, na França e no Brasil. Ao buscarmos as causas que explicavam as representações sociais diferentes em ambos os países, pudemos verificar a que ponto o ensino da filosofia na França é estável, enquanto que no Brasil ele é marcado por idas e vindas nos currículos escolares.

Palavras-chave: história, filosofia, Ensino Médio, França, Brasil.
\end{abstract}

\section{LA HISTORIA DE LA ENSEÑANZA DE LA FILOSOFÍA EN EL SISTEMA ESCOLAR FRANCÉS Y BRASILEÑO}

\section{Resumen}

El presente artículo tiene como objeto la historia de la enseñanza de la filosofía en el sistema escolar francés y brasileño. Nuestro objetivo es mostrar que, en Francia, donde la enseñanza de la filosofía está presente en los currículos escolares desde hace siglos, su importancia fue cuestionada apenas algunas veces a lo largo de la historia; es decir, su historia está marcada por una estabilidad. Por otro lado, se verificó que en Brasil la enseñanza de la filosofía está marcada por una inestabilidad. Llegamos a esa conclusión gracias a un análisis comparativo de discursos, cuya cuestión de investigación se refería a las representaciones sociales acerca de la filosofía, en Francia y en Brasil. Al buscar las causas que explicaban las representaciones sociales diferentes en ambos países, pudimos verificar a qué punto la enseñanza de la filosofía en Francia es estable, mientras que en Brasil está marcado por idas y venidas en los currículos escolares.

Palabras-clave: historia, filosofía, escuela secundaria, Francia, Brasil.

\section{THE HISTORY OF PHILOSOPHY TEACHING IN FRENCH AND BRAZILIAN SCHOOL SYSTEM}

\begin{abstract}
The object of this paper is the history of philosophy teaching in the French and Brazilian school system. Our aim is to show that in France, where philosophy teaching is present in school curricula since many centuries, its relevance was not questioned but a few times throughout History; in other words, its history is marked by a stability. On the other hand, we verified that in Brazil the philosophy teaching is marked by an instability. We
\end{abstract}


draw this conclusion thanks to a comparative discourse analysis, whose research question concerned the social representations about philosophy, in France and Brazil. By searching the causes that explain the different social representations in both countries, we could verify how much the philosophy teaching in France is stable, whereas in Brazil it's marked by comings and goings in the school curricula.

Keywords: history, philosophy, High School, France, Brazil.

\section{L'HISTOIRE DE L'ENSEIGNEMENT DE LA PHILOSOPHIE DANS LE SYSTÈME SCOLAIRE FRANÇAIS ET BRÉSILIEN}

\section{Résumé}

L'objet de cet article est l'histoire de l'enseignement de la philosophie dans le système scolaire français et brésilien. Notre but est de montrer qu'en France, où l'enseignement de la philosophie est présent dans les curricula scolaires depuis des siècles, sa pertinence n'a été mise en question que quelquefois au long de l'Histoire; autrement dit, son histoire est marquée par une stabilité. Par ailleurs, nous avons vérifié qu'au Brésil l'enseignement de la philosophie est marqué par une instabilité. Nous sommes arrivée à cette conclusion grâce à une analyse comparative de discours, dont la question de recherche a porté sur les représentations sociales concernant la philosophie, en France et au Brésil. En cherchant les causes qui expliquaient les représentations sociales différentes dans les deux pays, nous avons pu vérifier à quel point l'enseignement de la philosophie en France est stable, alors qu'au Brésil il est marqué par des allées et venues dans les curricula scolaires.

Mots-clés: histoire, philosophie, enseignement secondaire, France, Brésil. 


\section{Introdução}

$\mathrm{N}$

o decorrer de uma pesquisa em análise comparativa de discursos em que analisamos um corpus de livros didáticos de filosofia da França e do Brasil, deparamo-nos com a necessidade de explorarmos um pouco da história do ensino da filosofia nos dois países estudados. Comparado à história do ensino da filosofia na França, pudemos perceber o quanto o ensino da filosofia no Brasil é frágil e instável. Por isso, em nossa exposição, apresentaremos primeiramente a realidade do ensino da filosofia na França para, em seguida, apresentarmos a história do ensino da filosofia no Brasil.

Reconhecer tal fragilidade é importante, sobretudo no momento político atual, quando uma reforma do Ensino Médio alterará, mais uma vez, o modo pelo qual a filosofia vem sendo ensinada nas escolas brasileiras, a saber, durante os três anos do Ensino Médio. A vontade de suprimir ou reduzir a carga horária do ensino da filosofia nos países da América Latina parece não ser uma tendência exclusiva brasileira, como o demonstra o caso do Chile. (ÁVALOS VALDIVIA, 2017).

No Brasil, o ensino durante os três anos do Ensino Médio foi o resultado de uma resolução, submetida em 2006 pelo Conselho Nacional de Educação (CNE) a fim de tornar obrigatório nesse contexto o ensino da Filosofia e da Sociologia. Em 2 de junho de 2008, uma lei foi criada com esse objetivo: a Lei Federal oㅜ 11.684/08, que tornou definitivamente obrigatório o ensino dessas disciplinas em todas as escolas, sejam elas públicas ou privadas.

Nossa pesquisa tem como quadro teórico a análise comparativa de discursos. Trata-se de uma abordagem recente, que teve origem no Centro de pesquisa sobre discursos cotidianos e especializados, da Universidade de Paris 3 (Cediscor), nos anos 2000 e que, atualmente, vem ganhando espaço no Brasil, principalmente no grupo Diálogo, da Universidade de São Paulo.

O corpus da tese que realizamos na Université Sorbonne Paris Cité foi composto dos seguintes livros didáticos, publicados entre 2004 e 2012:

Corpus francês:

- CARDIN, Michel; HUISMAN, Denis; VERGEZ, André. Philosophie. Paris: Nathan, 2007.

- DELATTRE, Michel (Org.). Philosophie. Terminales L, ES, S. Paris: Hatier, 2012.

- HANSEN-LØVE, Laurence (Org.). Philosophie. Anthologie Terminales L. ES. S. Paris: Belin, 2004.

- PÉPIN, Charles. Ceci n'est pas un manuel de philosophie. Paris: Flammarion, 2010.

- RUSS, Jacqueline; LEGUIL, Clotilde. Les chemins de la pensée. Philosophie Terminales L - ES - S. Paris: Bordas, 2012.

- RUSS, Jacqueline; FARAGO, France. Nouvel abrégé de philosophie. Paris: Armand Colin, 2010. 
Corpus brasileiro:

- ARANHA, Maria Lúcia de Arruda; MARTINS, Maria Helena Pires. Filosofando: introdução à filosofia. São Paulo: Moderna, 2009.

- CHAUI, Marilena. Iniciação à filosofia. São Paulo: Ática, 2011.

- COTRIM, Gilberto; FERNANDES, Mirna. Fundamentos de filosofia. São Paulo: Saraiva, 2010.

A escolha do corpus teve como principal critério a busca da sua representatividade. (SARDÁ, 2015). Mediante a análise desse corpus, buscamos investigar quais eram as representações sociais da filosofia que nele estavam expressas, e chegamos, em linhas gerais, aos seguintes resultados:

- Nas duas comunidades, a filosofia é representada como uma disciplina abstrata, difícil e inútil (mas no Brasil essa representação tem mais força, segundo o que pudemos observar nos livros didáticos).

- No Brasil (mas também na França), os autores dos livros didáticos se posicionam contra essa representação social da filosofia, tida por abstrata, difícil e inútil.

- No Brasil, os discursos são mais politizados.

- Nas duas comunidades, a filosofia é representada como um conhecimento que ultrapassa os preconceitos do senso comum.

Algumas representações do ensino da filosofia também puderam ser verificadas:

- Na França, o ensino da filosofia é baseado no aprendizado de dois gêneros textuais: a dissertação e o comentário de texto. O discurso dos autores, nos livros didáticos franceses, segue a estrutura canônica desses gêneros. A finalidade do ensino da filosofia nos livros didáticos franceses é o desenvolvimento da reflexão crítica por intermédio desses dois gêneros textuais.

- No Brasil, os livros didáticos são constituídos por trechos bastante enciclopédicos e consagrados à história da filosofia. O enciclopedismo é provavelmente ligado aos exames nacionais, tais como o vestibular e o ENEM. A história da filosofia é uma tradição no ensino da filosofia no Brasil, inclusive no ensino secundário.

- No Brasil, a filosofia deve ajudar no desenvolvimento da capacidade argumentativa dos alunos. Na França também, pois para escrever uma dissertação ou comentário de texto é preciso saber argumentar.

Podemos dizer que buscamos, através da história do ensino da filosofia na França e no Brasil, as causas que explicavam tais representações sociais identificadas. Em geral, é nos livros didáticos brasileiros que os autores se explicam mais, justificam a utilidade da filosofia, como se tivessem de convencer seus leitores da importância dessa disciplina. $\mathrm{Na}$ França, os alunos simplesmente estudam a filosofia sem fazer semelhantes questionamentos. Nada mais natural, pois a história do ensino dessa disciplina é 
consideravelmente diferente nos dois países. Na França esse ensino é marcado pela estabilidade, enquanto que, no Brasil, pela instabilidade, conforme veremos a seguir.

\section{A estabilidade do ensino da Filosofia na França}

O ensino da filosofia é frequentemente tido na França por uma "especificidade francesa". Todo ano, é a disciplina de filosofia que inaugura as provas do baccalauréat ${ }^{1}$. Aparece, então, uma enxurrada de matérias na imprensa francesa sobre as provas de filosofia, frequentemente descritas como uma especificidade daquele país ${ }^{2}$. Esse discurso pode soar estranho aos brasileiros, já que no Brasil a filosofia também é ensinada nas escolas, como também está presente nos exames nacionais (vestibulares e Enem). Mas o ensino da filosofia na França, ao contrário do que acontece no Brasil, é marcado pela estabilidade. Dessa forma, muitos franceses veem essa disciplina como uma exclusividade do seu país, já que esse ensino se faz presente nos currículos escolares ao longo de várias décadas, e mesmo há séculos (trata-se de uma matéria escolar obrigatória desde o início do século XIX). Com efeito, se a filosofia não é uma especificidade francesa, na França ela se tornou, no entanto, uma tradição, pois seu ensino no secundário quase nunca foi interrompido (SHERRINGHAM, 2006, p. 61, cita uma única interrupção entre os anos de 1852 a 1863), ainda que a disciplina tenha sido ameaçada em outros momentos da sua história.

"A filosofia é, desde o Primeiro Império (inspirando-se na tradição dos colégios jesuítas), e com exceção de um eclipse entre 1852 a 1863, uma matéria obrigatória no ensino secundário, circunscrita ao último ano do liceu [Ensino Médio]". (SHERRINGHAM, 2006, p. 61) ${ }^{3}$. Essa citação pode dar a entender que o ensino da filosofia teve somente um período crítico na França, entre os anos de 1852 a 1863. Assinalemos, pelo contrário, ao menos um outro período que julgamos crítico para o ensino da filosofia na França: a década de 70, conforme veremos adiante.

A supressão da filosofia dos currículos durante os anos 1852-1863 se deve a uma reforma nomeada "bifurcação", como nos lembra Hulin (1982, p. 217):

Durante o Segundo Império, uma importante mudança foi realizada por $\mathrm{H}$. Fourtoul (1852) no ensino secundário, dando um novo lugar às ciências nos liceus e tentando renovar os métodos de ensino. Cientistas, entre outros, participaram da reforma que ficou conhecida sob o nome de "bifurcação". [...] A reforma foi muito criticada e, por razões diversas, foi um fracasso. A "bifurcação" foi suprimida em 1864 por Victor Duruy. ${ }^{4}$ (p. 217).

\footnotetext{
1 Baccalauréat: "Grau universitário francês (criado em 1808) conferido após exames que finalizam os estudos secundários" [traduçao nossa]. Cf. Dicionário eletrônico Le Grand Robert de la Langue Française, 2005.

2 Ver, por exemplo: LE ROUX, Gaëlle. L'épreuve de "philo" au bac , une spécificité française. France 24, 2011: Disponível em: <http://www.france24.com/fr/20110615-france-enseignement-bac-lycee-epreuvephilosophie-specificite-francaise/>. Acesso em: 25 jul. 2018.

${ }^{3}$ No original: "La philosophie est depuis le Premier Empire (s'inspirant de la tradition des collèges des jésuites), et à l'exception d'une éclipse de 1852 à 1863, une matière obligatoire dans l'enseignement secondaire, circonscrite à la dernière année du lycée".

${ }^{4}$ No original: "Pendant le Second Empire un important changement fut apporté par H. Fortoul (1852) à l'enseignement secondaire, donnant une place nouvelle aux sciences dans les lycées et tentant de rénover les méthodes d'enseignement. Des savants entre autres participèrent à la réforme qui est connue sous le nom de 'bifurcation'. [...] La réforme fut très critiquée et pour des raisons diverses ce fut un échec. La 'bifurcation' fut supprimée en 1864 par Victor Duruy”.
} 
Observamos o surgimento, nesse período, de um discurso que considerava a filosofia como uma disciplina abstrata e desnecessária. Foi então que a substituíram pela classe de lógica:

No artigo 4 do decreto de 10 de abril de 1852 que aprova o plano de estudos adotado pelo Conselho Superior de Instrução Pública, encontra-se esta menção: “... um último ano, dito de lógica, obrigatório para as duas categorias de alunos [...], tem particularmente por objeto a exposição das operações do entendimento e a aplicação dos princípios gerais da arte de pensar ao estudo das Ciências e das Letras". 5 (JACQUIN , 1957, p. 384).

Jacquin (1957) defende que "sob esse nome [de lógica] eram abordadas questões relativas a outras partes da filosofia. Segundo os próprios textos oficiais, era somente um aliviamento dos programas"6. (p. 382). Todavia, isso não exclui a afirmação de Fortoul, que considerava que era preciso evitar as "especulações vãs": "O ensino da filosofia era mantido, mas anexado aos elementos da lógica, que deveria fortalecer os espíritos sem expô-los ao perigo das especulações vãs"7 [grifo nosso]. (FORTOUL apud JACQUIN, 1957, p. 384). Em nosso entendimento, o fato de mudar o nome da disciplina de filosofia para lógica - além dessa preocupação com a ciência - é um sinal importante. Aliás, quando consultamos alguns livros didáticos mais antigos, observamos que, por volta do ano de 1880, Paul Janet, autor do Traité élémentaire de philosophie à l'usage des classes - livro didático adotado no ensino secundário no período de 1879 a 1889, segundo informações de Poucet (1999) -, já tentava convencer os leitores da utilidade da filosofia. Encontramos nesse livro a mesma insistência sobre a utilidade da filosofia que aquela dos livros didáticos brasileiros. (SARDÁ, 2015). Janet (1882) apresenta o que supomos ser as representações sociais relativas à filosofia de então, argumentando em favor dessa disciplina; tudo isso na conclusão do seu tratado (a partir da página 823):

Reservamos para o final deste tratado algumas questões que se costuma tratar no início da ciência, mas que são mais apropriadas na conclusão, pois se está então em condições de falar a respeito disso com conhecimento de causa. São, por exemplo, a questão da utilidade e da importância da filosofia e a questão das suas relações com outras ciências. ${ }^{8}$ (JANET , 1882 [1879], p. 823).

Janet (1882 [1879]), no parágrafo sobre a utilidade da filosofia, afirma:

654. Utilidade da filosofia. - Nós acabamos de ver qual é o valor intrínseco da filosofia. Consideremos agora a sua utilidade. Essa utilidade pode ser considerada de dois pontos de vista: a) do ponto de vista da inteligência; b) do ponto de vista da vontade.

\footnotetext{
${ }^{5}$ No original: "Dans l'article 4 du décret du 10 avril 1852 qui approuve le plan d'études adopté par le Conseil Supérieur de l'Instruction Publique, on trouve cette mention: '[...] une dernière année, dite de logique, obligatoire pour les deux catégories d'élèves [...], a particulièrement pour objet l'exposition des opérations de l'entendement et l'application des principes généraux de l'art de penser à l'étude des sciences et des lettres"”.

${ }^{6}$ No original: "sous ce nom [de logique] étaient abordées bien des questions relevant des autres parties de la philosophie. D'après les textes officiels eux-mêmes, c'était seulement un all[è]gement des programmes".

${ }^{7}$ No original: "L'enseignement de la philosophie était maintenu, mais rattaché aux éléments de la logique, qui devait fortifier les esprits sans les exposer au péril des spéculations vaines".

8 No original: "Nous avons réservé pour la fin de ce traité quelques questions que l'on traite d'ordinaire au début de la science, mais qui sont plus à leur place dans la conclusion, car on est alors en mesure d'en parler avec connaissance de cause. Ce sont, par exemple, la question de l'utilité et de l'importance de la philosophie et celle de ses rapports avec les autres sciences".
} 
a) A filosofia exerce o espírito no exame e na discussão das questões abstratas. [...] b) A filosofia é útil para a direção da vontade, pois ela ensina o homem a se conhecer a si mesmo [...]. Ela Ihe ensina a excelência de suas faculdades, a dignidade de sua natureza, e lhe ensina a não tratar nem a si mesmo nem aos outros homens como coisas, como instrumentos, mas a respeitar neles e em si a personalidade humana, a liberdade. ${ }^{9}$ (JANET , 1882 [1879], p. 824).

É notável, no excerto acima, que o tratamento de questões abstratas pela filosofia seja um argumento favorável à utilidade dessa disciplina. Valores inversos aos das representações sociais que constatamos nos livros de hoje (cf. introdução).

Em seu tratado, Janet (1882 [1879]) se opõe ao discurso do positivismo:

655. Objeções contra a filosofia. - Positivismo - Criticismo. - Escola histórica. - Muitas objeções foram levantadas em nossos dias contra a filosofia, umas partindo do ponto de vista das ciências positivas, outras do espírito crítico, outras, enfim, do espírito histórico. Seja qual for a diferença desses pontos de vista, as dificuldades propostas são quase sempre as mesmas. ${ }^{10}$ (JANET , 1882 [1879], p. 824).

Veremos na próxima seção como a influência do positivismo no Brasil desempenhou um papel na supressão da filosofia durante a ditadura militar. As afirmações de Janet (1882 [1879]) mostram que, se a filosofia não foi suprimida durante esse período na França, a "ameaça" dos ideais positivistas não era menos real.

Malgrado os eventos citados, a filosofia sobreviveu até os anos 1950 aproximadamente, com um estatuto muito importante na França. Segundo o filósofo e historiador da filosofia Châtelet (1970), foi por volta do ano de 1955 que a filosofia começou a perder seu espaço em proveito de outras disciplinas das ciências humanas e sociais:

Desde a Liberação, o ensino da filosofia é, com efeito, objeto de reduções progressivas. Praticamente mestre do baccalauréat de "filosofia-letras", parte determinante no de "ciências experimentais", parte interessada no de "matemática", há uns quinze anos, o professor do secundário viu pouco a pouco o seu império se reduzir. Não somente os "científicos" Ihe fazem uma concorrência grave, mas ainda seu velho adversário, o dito professor de francês, o alcança e o iguala. No ensino superior, duas das corveias mais espetaculares da grande sabedoria adquiriram uma independência ameaçadora, a psicologia e a sociologia $[\ldots]^{11}$ (p. 11).

\footnotetext{
${ }^{9}$ No original: "654. Utilité de la philosophie. - Nous venons de voir quelle est la valeur intrinsèque de la philosophie. Considérons-en maintenant l'utilité. Cette utilité peut être considérée à deux points de vue : a) au point de vue de l'intelligence; b) au point de vue de la volonté. a) La philosophie exerce l'esprit à l'examen et à la discussion des questions abstraites. [...] b) La philosophie est utile à la direction de la volonté car elle apprend à l'homme à se connaître lui-même [...]. Elle lui apprend l'excellence de ses facultés, la dignité de sa nature, et lui apprend à ne traiter ni lui-même, ni les autres hommes comme des choses, comme des instruments, mais à respecter en eux et en soi la personnalité humaine, la liberté [...]".

10 No original: "655. Objections contre la philosophie. - Positivisme - Criticisme. - École historique. Beaucoup d'objections ont été élevées de nos jours contre la philosophie, les un[e]s partant du point de vue des sciences positives, les autres de l'esprit critique, les autres enfin de l'esprit historique. Quelle que soit la différence de ces points de vue, les difficultés proposées sont toujours à peu près les mêmes".

11 No original: "Depuis la Libération, l'enseignement de la philosophie est l'objet, en effet, de réductions progressives. Pratiquement maître du baccalauréat de «philosophie-lettres», partie déterminante dans celui de «sciences expérimentales», partie prenante dans celui de «mathématiques», il y a quelque quinze ans, le professeur du secondaire a vu peu à peu se réduire son empire. Non seulement les «scientifiques» lui font une concurrence grave, mais encore son vieil adversaire, le professeur dit de français le rejoint et l'égale. Dans l'enseignement supérieur, deux des couvées les plus spectaculaires de la grande sagesse ont acquis une indépendance menaçante, la psychologie et la sociologie [...]".
} 
No que concerne a um período ainda mais recente, a saber, em março de 1979, o Groupe de recherches sur l'enseignement philosophique - Greph, que contava, entre seus membros, com a presença do filósofo Jacques Derrida, lançou uma chamada para a reunião dos États Généraux de la Philosophie [Estados Gerais da Filosofia] (GREPH, 1979, p. 5), cujo objetivo era de lutar contra a precariedade do ensino e da pesquisa nesse domínio. Os États Généraux de la Philosophie ocorreram nos dias "16 e 17 de junho [1979] no Grande Anfiteatro da Sorbonne"12 (p. 5). No texto da chamada (p. 9-10) fala-se das "ofensivas contra a filosofia" e afirma-se que "a vontade de liquidação [da filosofia] nunca foi tão premente"13.

No Quadro Negro esboçado pelo Greph (cf. p. 11-14), fala-se da Reforma Haby, que está entre as que "enquadraram a massificação do sistema educativo" (TROGER, 2009, p. 17) ${ }^{14}$, como a responsável por essa ameaça à filosofia:

A demonstração disso deve ser feita, e ela é fácil: se não se fizer nada, a política atual reservaria à filosofia o futuro mais sombrio [...] É preciso saber que a lei sobre a reforma do sistema educativo (dita "Reforma Haby"), votada em junho de 1975, só fixou um quadro geral e princípios pedagógicos. Quanto ao conteúdo do ensino secundário, disciplina por disciplina, e na sua carga horária, ele foi em larga medida, sob a demanda insistente do governo, abandonado ao domínio regulamentário. Trata-se, portanto, de decretos de aplicação que regulamentarão o destino da filosofia no ensino secundário. É claro, as consequências disso serão sentidas, inevitavelmente, no ensino e na pesquisa universitárias ${ }^{15}$. (GREPH , 1979, p. 11).

A reforma Haby estava para entrar em vigor em 1981 (ibid., p. 11), quando dois projetos concernentes à filosofia foram apresentados. No primeiro, o número de horas para a filosofia continuaria sendo o mesmo, embora a intenção fosse de transformar o número de horas obrigatórias em horas facultativas. O que foi considerado perigoso pelos professores, já que "a filosofia, tendo a reputação de uma disciplina 'difícil' [...] previa-se facilmente que a escolha de uma opção tão espetacularmente desfavorecida seria

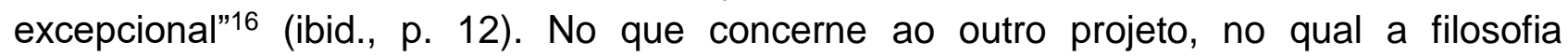
supostamente deveria passar de quatro para três horas obrigatórias, as consequências teriam sido bem mais graves, segundo o Greph: “1. 'Desemprego técnico' [...] 2. Multiplicação e quase-generalização dos serviços de ensino espalhados em vários municípios [...] 3. Parada imediata e suspensão por vários anos do recrutamento dos professores de filosofia". ${ }^{17}$ (ibid., p. 13).

\footnotetext{
12 No original: "les 16 et 17 juin [1979] dans le Grand Amphithéâtre de la Sorbonne".

${ }^{13}$ No original: "offensives contre la philosophie"; "la volonté de liquidation [de la philosophie] n'a jamais été si pressante".

14 No original: "ont encadré la massification du système éducatif".

${ }^{15}$ No original: "La démonstration doit en être faite et elle est facile: si on laisse faire, la politique actuelle réserverait à la philosophie l'avenir le plus sombre. [...] II faut savoir que la loi portant réforme du système éducatif (dite 'Réforme Haby '), voté en juin 1975, n'a fixé qu'un cadre général et des principes pédagogiques. Quant au contenu de l'enseignement secondaire, discipline par discipline, et dans sa répartition horaire, il a été pour une large part, à la demande insistante du gouvernement, abandonné au domaine réglementaire. $\mathrm{Ce}$ sont donc des décrets d'application qui régleront le sort de la philosophie dans l'enseignement secondaire. Bien entendu, les conséquences s'en feront sentir, immanquablement, dans l'enseignement et dans la recherche universitaires".

${ }^{16}$ No original: "la philosophie ayant la réputation d'être une discipline 'difficile' [...] on prévo[ya]it facilement que le choix d'une option aussi spectaculairement défavorisée serait exceptionnel".

17 No original: "1. Mise au 'chômage technique' [...] 2. Multiplication et quasi-généralisation des services d'enseignement réparties sur plusieurs communes [...] 3. Arrêt immédiat et suspension pour plusieurs années du recrutement des professeurs de philosophie".
} 
Podemos consultar, nos États Généraux de la Philosophie, as comunicações de todos os participantes, que foram transcritas no livro publicado pela editora Flammarion. Para Vladimir Jankélévitch, por exemplo, o objetivo da Reforma Haby era "obter pouco a pouco a falência do ensino filosófico, reduzindo de ano em ano o número de vagas dos concursos, suprimindo cargos, substituindo nas Escolas Normais a cultura filosófica por um aprendizado psicológico considerado mais rentável e mais utilitário [...] $]^{18}$ (GREPH, 1979, p. 23) [grifo nosso].

A palavra-chave "inutilidade" está sempre presente no contexto da época para desqualificar a filosofia. O filósofo François Châtelet denuncia a situação do ensino da filosofia, já tida por inútil em sua época:

[S]obre o plano institucional, a filosofia recebe golpes muito duros relativos ao seu ensino. Se eu tomo o caso particular da França, reduz-se as horas consagradas ao ensino filosófico em nome da rentabilidade, dos imperativos da formação profissional, repetindo-se este velho lema: a filosofia é inútil, é tempo perdido; neste mundo da produção, é preciso pensar de outra maneira". ${ }^{19}$ (CHÂTELET, 1992 [1979], p. 215).

No entanto, vemos que a filosofia se manteve no ensino secundário na França, malgrado alguns períodos difíceis. Isso explica por que, nos livros didáticos franceses, as representações sociais que desvalorizam a filosofia são menos fortes do que nos livros brasileiros. Todavia, mapeamos algumas reprovações a essa disciplina escolar no livro didático de Pépin (cf. corpus acima) - que se posiciona contra essas representações, é claro. Podemos dizer, grosso modo, que a filosofia não está "tranquila" em lugar algum, pois não sendo "rentável" - não mais do que outras disciplinas das ciências humanas -, ela é uma das primeiras disciplinas ameaçadas nos momentos de crise. Na França, a filosofia tem uma força considerável comparada a outros países, mas isso não impediu, para citar um exemplo atual, que uma petição para "salvar" o Collège International de Philosophie tenha circulado no ano de 2014, em um momento de crise financeira na França ${ }^{20}$.

No que concerne às reformas do ensino, observamos que na França elas são sempre assunto de debates na imprensa. Segundo Pinto (2007), na França "os debates em torno dos métodos e programas de ensino da disciplina [de filosofia] [...] são frequentemente tão vigorosos e apaixonados quanto os debates de ordem 'teórica"”21, o que mostra a força da filosofia como instituição de ensino nesse país.

A filosofia na França só é ensinada na classe Terminale, correspondente ao último ano do Liceu (Ensino Médio). Esse fato é objeto de críticas recorrentes. Já no texto do Greph (1979), observamos uma reivindicação para que se ensine a filosofia desde o

\footnotetext{
18 No original: "d'obtenir peu à peu le dépérissement de l'enseignement philosophique en réduisant d'année en année le nombre des places mises au concours, en supprimant des postes, en remplaçant dans les Écoles normales la culture philosophique par un apprentissage psychologique considéré comme plus rentable et plus utilitaire".

19 No original: "sur le plan institutionnel, la philosophie reçoit des coups très durs concernant son enseignement. Si je prends le cas particulier de la France, on réduit les heures consacrées à l'enseignement philosophique au nom de la rentabilité, des impératifs de la formation professionnelle, en répétant ce vieux truc: la philosophie est inutile, c'est du temps perdu; dans ce monde de la production, il faut penser autrement".

20 Disponível em: <https://www.change.org/p/sauvons-le-coll\%C3\%A8ge-international-de-philosophie-pourle-droit-\%C3\%A0-la-philosophie-pour-tous>. Acesso em: 25 jul. 2018.

${ }^{21}$ No original: "les débats autour des méthodes et des programmes de la discipline [de philosophie] [...] sont souvent aussi vigoureux et passionnés que les débats d'ordre 'théorique'".
} 
primeiro ano do Ensino Médio (classe de Seconde):

A médio prazo, para responder à demanda e às necessidades, será preciso ampliar o ensino filosófico a todo o segundo ciclo dos liceus, do primeiro ao terceiro ano do Ensino Médio (o horário do terceiro ano podendo ser modulado) e a todos os alunos dos liceus e das escolas técnicas. Essa extensão é possível e necessária, experiências recentes o demonstraram. Ela corresponde não somente a aptidões, mas a uma demanda ampla e profunda dos alunos que não estão ainda no terceiro ano. ${ }^{22}$ (GREPH , 1979, p. 15).

O pedido por uma ampliação do ensino da filosofia a todo o secundário ainda é atual na França. Na época do Greph, não somente os professores reivindicavam essa ampliação, como também os alunos ${ }^{23}$. Nos dias atuais, a filosofia ensinada somente na classe Terminale parece ser desencorajante para os jovens estudantes. De acordo com Enthoven (2010, p. 7),

[a]o limitar o ensino da filosofia à classe Terminale, o sistema educativo [...] faz, frequentemente, da alegria de pensar um calvário. Ao invés de levar tempo, ao longo de vários anos, para despertar os alunos e habituá-los aos deliciosos paradoxos, de Ihes mostrar que a filosofia apenas traduz precisamente as questões que eles se perguntam desde sempre, a escola restringe os futuros bacheliers a engolir, em alguns meses, um monte de noções fundamentais e todas as dificuldades de um léxico desencarnado. ${ }^{24}$

Pinto (1987), em suas pesquisas sobre a "sociologia da filosofia", denuncia uma "cultura de urgência" no ensino dessa disciplina na França:

Esta disciplina deve dotar da maneira mais econômica (durante um ano, em algumas horas por semana) os indivíduos que ela atinge dos meios que thes permitam alcançar o nível escolarmente definido da "reflexão" "autônoma" e "rigorosa". Mas, longe de se apresentar pelo que ela é, essa "cultura de urgência", para retomar os termos de Pierre Bourdieu, pretende decorrer de puras exigências intelectuais. ${ }^{25}$ (p. 17-18).

${ }^{22}$ No original: "A moyen terme, pour répondre à la demande et aux besoins, il faudra étendre l'enseignement philosophique à tout le second cycle des lycées, de la seconde à la terminale incluse (l'horaire en terminale pouvant être modulé) et à tous les élèves des lycées et L.E.P. Cette extension est possible et nécessaire, des expériences récentes l'ont démontré. Elle correspond non seulement à des aptitudes mais à une demande large et profonde chez des élèves qui ne sont pas encore en terminale".

${ }^{23} \mathrm{O}$ Greph acabou não vendo essa reivindicação ser atendida. Em sua biografia sobre Derrida, Powell (2006) assinala, além disso, que o Greph não teve uma história de sucessos: "Derrida formed a friendship with Sarah Kofman, Jean-Luc Nancy and Phillipe Lacoue-Labarthe in 1974 which was to lead to the foundation, in 1975, of the Research Group on the Teaching of Philosophy [...], a project which was to have a generally unsuccessful history in terms of its achievements, as Derrida saw them, but was nonetheless worth the effort". (POWELL, 2006, p. 113).

24 No original: "[e]n limitant l'enseignement de la philosophie à la classe de Terminale, le système éducatif [...] fait, trop souvent, un calvaire du bonheur de penser. Au lieu de prendre le temps, sur plusieurs années, d'éveiller les élèves et de les habituer à de délicieux paradoxes, de leur montrer que la philosophie ne fait que traduire précisément les questions qu'ils se posent eux-mêmes depuis toujours, l'école contraint les futurs bacheliers à ingurgiter, en quelques mois, une foule de notions fondamentales et toutes les difficultés d'un lexique désincarné".

${ }^{25}$ No original: "Cette discipline doit doter de la façon la plus économique (pendant une année, à raison de quelques heures par semaine) les individus qu'elle touche des moyens leur permettant d'accéder au niveau scolairement défini de la 'réflexion' 'autonome' et 'rigoureuse'. Mais, loin de se présenter pour ce qu'elle est, cette 'culture d'urgence', pour reprendre les termes de Pierre Bourdieu, prétend découler de pures exigences intellectuelles". 
Parece-nos, em suma, que o ensino da filosofia na França apresenta virtudes consideráveis. Para Sherringham (2006), entre os "traços distintivos da filosofia" nesse país, encontra-se "uma vocação generalista que visa à formação do 'cidadão esclarecido', um ensino elementar que evita a dupla armadilha do enciclopedismo e da erudição especializada, uma pedagogia da liberdade que defende a expressão organizada da reflexão e do julgamento" 26 . Todavia, essas competências devem ser desenvolvidas tão rapidamente, que nos perguntamos sobre o seu êxito junto aos alunos. Esse parece ser um dos aspectos negativos da estabilidade do ensino da filosofia na França: se por um lado ela não é frequentemente suprimida dos currículos escolares, por outro as coisas parecem não mudar quando se trata de ensiná-la mais cedo, de modo a satisfazer às reivindicações de professores e de alunos.

\section{A instabilidade do ensino da Filosofia no Brasil}

O ensino da filosofia no Brasil é marcado pela instabilidade. Assim como na França, a filosofia está ligada, no Brasil, à tradição jesuíta (SHERRINGHAM, 2006); mas, contrariamente ao que acontece na França, em nosso país esse ensino é marcado por uma longa história de "idas e vindas". O ensino da filosofia (e da sociologia) tornou-se obrigatório no Brasil, em todas as escolas, públicas e privadas, em 2 de junho de 2008, data da promulgação da Lei Federal no $11.684^{27}$. A implementação desse ensino obrigatório é fruto de uma luta que remonta ao período posterior à ditadura militar, pois a filosofia foi suprimida dos currículos escolares no ano de 1971, quando a lei no $5.692 / 71$ proibiu o seu ensino no país. Antes dessa interrupção, o ensino da filosofia era obrigatório desde 1942, no governo de Getúlio Vargas, e mesmo antes: outras interrupções ocorreram, mas esse ensino figura nos programas brasileiros "desde a criação da primeira escola de ensino secundário da companhia de Jesus em Salvador da Bahia em 1553". (KOHAN, 2007, p. 78) ${ }^{28}$.

Chamamos a atenção para o fato de que o ensino da filosofia no Brasil sofreu verdadeiros momentos de cisão, contrariamente ao que vimos em relação à França. Neste país, a filosofia não foi suprimida dos currículos no auge do positivismo, como foi o caso no Brasil. Mais tarde, nos anos 1970, enquanto que na França se instaurava um debate sobre o ensino da filosofia envolvendo professores, alunos e até mesmo filósofos renomados ${ }^{29}$, no Brasil o diálogo não pôde ser estabelecido, pois vivíamos sob o regime militar ditatorial, que, como sabemos, suprimiu a filosofia dos currículos desse período.

Alves (2002) divide em três momentos a história do ensino da filosofia no Brasil. Do período colonial até a República, a filosofia é "presença garantida" nos currículos; da Primeira República ao Golpe Civil Militar de 1964, ela é "presença indefinida"; por fim, o período ditatorial (pós-1964) é caracterizado por uma "ausência definida". Comentaremos

\footnotetext{
${ }^{26}$ No original: "une vocation généraliste qui vise la formation du 'citoyen éclairé', un enseignement élémentaire évitant le double écueil de l'encyclopédisme et de l'érudition spécialisée, une pédagogie de la liberté qui soutient l'expression organisée de la réflexion et du jugement".

27 PRESIDÊNCIA DA REPÚBLICA FEDERATIVA DO BRASIL. Lei ㄲo 11.684, de 2 de junho de 2008. Disponível em: <http://www.planalto.gov.br/ccivil_03/_Ato2007-2010/2008/Lei/L11684.htm>.

${ }^{28}$ No original: "depuis la création de la première école d'enseignement secondaire de la compagnie de Jésus à Salvador de Bahia en 1553". Salvo indicação contrária, todas as traduções, neste artigo, são de nossa responsabilidade.

29 Debate organizado pelo Groupe de recherches sur l'enseignement philosophique - Greph, conforme vimos na seção anterior.
} 
mais detalhadamente esses momentos nos parágrafos a seguir.

A "presença garantida" inicia-se com os jesuítas e é marcada pela hegemonia da Companhia de Jesus, cuja pedagogia continuará forte até o advento das reformas pombalinas. Esse ensino, segundo Alves (2002, p. 12), era destinado somente a uma parcela muito pequena da população:

[...] esses cursos eram destinados aos "homens bons" da Colônia, os proprietários, senhores de engenho etc., estando os índios, os negros e os brancos pobres excluídos desse processo. Quando muito tinham acesso aos cursos elementares e aos de humanidades, que eram organizados pelos jesuítas para os "externos", isto é, "para crianças e jovens não pertencentes à Companhia de Jesus" [...]

A filosofia era ministrada nos studia superiora, e, por isso, acessível somente àqueles poucos privilegiados, pois "permitia [...] um grau mais elevado de cultura, formação e profissionalização". (ALVES, 2002, p. 12). No período pombalino, a presença da filosofia continuava garantida devido à sua "utilidade", já que era tida por uma "ciência natural". Essa visão cientificista persistirá no período seguinte - o Período Imperial -, influenciado pelo Positivismo.

Em 1808 acontece a transferência da sede do reino português para o Rio de Janeiro [...] O tempo de estadia da Corte portuguesa no Brasil Colônia [...] foi marcado pelas mudanças drásticas que provocou no panorama cultural da Colônia, especialmente devido à abertura dos portos brasileiros ao comércio mundial, que propiciou a "influência de novas ideias na vida da colônia". ([CARTOLANO, 1985], p. 26) (ALVES, 2002, p. 19).

Alves (2002, p. 20) ainda mostra que os "livros textos" de várias disciplinas eram importados da França e que o Positivismo "passou a integrar o 'ideário nacional', principalmente 'com o retorno de brasileiros que estudavam na Escola Politécnica de Paris (onde lecionava Auguste Comte)"'.

A "presença indefinida" é a marca do período seguinte. Da Primeira República ao Golpe Civil Militar de 1964, o ensino da filosofia torna-se mais instável no Brasil. Em 1889, com a proclamação da República, que ocorreu devido à influência positivista, "agudas reformas" ocorreram no campo educacional. O objetivo dessas reformas era "formar uma nova 'elite' para um novo Estado". (ALVES, 2002, p. 25). Temos o advento de uma "escola pública laica". Benjamin Constant propõe diversas reformas que acabam não acontecendo, mas que representam "o início da influência mais direta do positivismo nas reformas educacionais e pela imediata repercussão disto no caráter da presença da filosofia no ensino secundário nos primórdios da nossa República". (idem, p. 27). Ao se adotar a "hierarquia das ciências" de Auguste Comte, "pela primeira vez a filosofia, enquanto disciplina escolar, fica ausente do currículo, desde a organização do ensino na Colônia" (ALVES, 2002, p. 27), o que implicará nessa "indefinição" sobre a presença ou a ausência da filosofia no ensino secundário durante o Período Republicano.

O período posterior a 1930 também foi caracterizado por reformas no campo educacional, que acompanharam as reformas mais gerais feitas por Getúlio Vargas. No que concerne ao ensino secundário, temos a Reforma Francisco Campos (1932) e a Reforma Gustavo Capanema (1942). Ambas as reformas tinham como horizonte a questão do "aumento da demanda por mão-de-obra qualificada para a indústria". (ALVES, 2002, p. 32). 
A reforma Francisco Campos (1932) reestruturou o ensino secundário e, consequentemente, interferiu no lugar dado à Filosofia:

[O ensino secundário] ficou dividido em dois ciclos: um fundamental, de cinco anos, obrigatório para o ingresso nas escolas superiores, dava uma formação básica geral; e outro complementar, de dois anos, que preparava para o ingresso nas escolas de direito, medicina e engenharia. A filosofia passou a compor o currículo do ciclo complementar, como história da filosofia e como lógica. (ALVES, 2002, p. 32) [grifo nosso].

Com a Reforma Gustavo Capanema (1942), o ensino continuava tendo, nas palavras de Alves (2002), um caráter enciclopédico e elitista, e seguiu estruturado em dois ciclos, sendo quatro anos de "ginásio" e três anos de "colégio". A filosofia estava presente no "colégio", mas em grau diferente conforme a subdivisão em que o aluno se encontrasse:

[O colégio era] subdividido em dois cursos paralelos: o clássico, que enfatizava a formação intelectual; e o científico, que era marcado por um estudo maior das ciências. A filosofia era indicada para o colégio como disciplina obrigatória na $2^{\mathrm{a}} \mathrm{e}$ $3^{a}$ séries do curso clássico e na $3^{a}$ série do científico. (CARTOLANO, 1985, p. 58) (ALVES, 2002, p. 33).

O período posterior a 1930 foi, portanto, caracterizado por diversas mudanças no campo educacional, que foram levando a uma redução cada vez maior da carga horária destinada à filosofia. Assim, antes do Golpe Civil-Militar de 1964, a filosofia já estava num "processo de 'extinção' gradativa do currículo" (ALVES, 2002, p. 34), que só veio a se agravar durante o período ditatorial.

O período de "ausência definida" corresponde ao período ditatorial. Sabe-se que a ditadura militar aconteceu no período entre 1964 e 1985. Segundo o sociólogo e filósofo Michael Löwy (2005, p. 7), "depois do Chile, a ditadura militar brasileira foi uma das mais tenazes do continente: vinte e um anos de 'estado de exceção"' 30 . O golpe de Estado, que ocorreu dia 31 de março de 1964, marcava a saída do governo do presidente João Goulart: "o golpe de Estado de 1964 e a instalação do governo de Castelo Branco correspondem a uma virada decisiva em direção ao fim do bloco histórico de 1930-1964 e a inauguração de um novo bloco"31. (SALLES, 2005, p. 59). Após o golpe de Estado, assistiu-se, no decorrer dos anos, a uma série de atos institucionais (Al). Teles \& Safatle (2010) fazem uma reflexão interessante sobre a relação entre o direito e a ditadura no Brasil da época:

[...] uma das características mais decisivas da ditadura brasileira era sua legalidade aparente ou, para ser mais preciso, a sua capacidade de reduzir a legalidade à dimensão da aparência. Tínhamos eleições com direito a partido de oposição, editoras que publicavam livros de Marx, Lenin, Celso Furtado, músicas de protesto, governo que assinava tratados internacionais contra a tortura, mas, no fundo, sabíamos que tudo isto estava submetido à decisão arbitrária de um poder soberano que se colocava fora do ordenamento jurídico. Quando era conveniente, as regras eleitorais eram modificadas, os livros apreendidos, as músicas censuradas, alguém desaparecia. Em suma, a lei era suspensa. (TELES; SAFATLE, 2010, p. 11).

\footnotetext{
${ }^{30}$ No original: "[a]près le Chili, la dictature militaire brésilienne a été une des plus tenaces du continent: vingt et une années d' 'état d'exception"'.

${ }^{31}$ No original: "le coup d'État de 1964 et l'installation du gouvernement Castelo Branco correspondent à un tournant décisif vers la fin du bloc historique de 1930-1964 et l'inauguration d'un nouveau bloc".
} 
O ano de 1971 marca a supressão do ensino da filosofia dos currículos escolares, o que gerou protestos, e isso até o ano de 1982:

Com a promulgação da Lei 4.024/61, a Filosofia deixa de ser disciplina obrigatória e passa a disciplina complementar nos currículos escolares. A Lei 5.692, promulgada em 1971, em pleno regime militar, extingue a Filosofia dos currículos, destarte as reações e mobilizações ocorridas no país em prol de sua manutenção/retorno aos currículos escolares. Tais mobilizações estimulam reações em diversos níveis e, por meio do Parecer 7.044/82, do então Conselho Federal de Educação - CFE -, abrem-se possibilidades para o retorno da disciplina de Filosofia aos currículos do Ensino Médio. (RODRIGUES, 2012, p. 71).

Os livros didáticos brasileiros que integraram o nosso corpus (cf. introdução acima) exploram diretamente o tema da ditadura. O enunciado a seguir, de Aranha \& Martins, diz muito sobre a polêmica existente em torno das razões da supressão da filosofia durante a ditadura militar:

Sempre há os que ignoram os filósofos. Mas não é o caso dos ditadores: estes os fazem calar, pela censura, porque bem sabem quanto eles ameaçam seu poder. (ARANHA \& MARTINS , p. 17).

Afirma-se, com frequência, que a filosofia foi suprimida dos currículos durante a ditadura militar porque ela favorece a reflexão, mas há historiadores da educação que não concordam com essa ideia. Carminati (2004), por exemplo, realizou uma pesquisa bibliográfica sobre esse assunto e defende que, para alguns, a filosofia era considerada perigosa, pois ela podia incitar os jovens a lutar contra o regime militar, enquanto que para outros, a verdadeira razão da supressão desse ensino era a virada "profissionalizante" que se queria dar ao ensino secundário brasileiro. Todavia, Carminati (2004) lembra que as disciplinas Educação Moral e Cívica (EMC) e Organização Social e Política do Brasil (OSPB), que substituíram a filosofia nos currículos durante a ditadura, tinham um caráter "acrítico". Nas palavras do autor (2004),

[...] tudo indica que, naquele momento, início da década de 1970, uma filosofia submissa e obediente parecia pouco rentável aos olhos dos tecnocratas, tratandose de uma disciplina com pouca ou nenhuma "utilidade" para um país que havia feito uma opção clara por um projeto de desenvolvimento". (CARMINATI, 2004, p. 7).

Para Ferreira (2009, p. 49), a perspectiva, nesse período, "era de internacionalização do país e, consequentemente, sua adaptação às sociedades capitalistas centrais". Aranha \& Martins apresentam também esse aspecto em seu livro didático:

A chamada educação tecnicista, implantada no Brasil durante a ditadura militar, tinha orientação positivista e baseava-se nos ideais de organização, objetividade, eficiência e produtividade. O planejamento deveria definir objetivos instrucionais e operacionais rigorosamente esmiuçados, estabelecendo o ordenamento sequencial das metas a serem atingidas". (ARANHA \& MARTINS , p. 391).

Em resumo, o positivismo era utilizado para justificar a mudança em direção a um ensino tecnicista. Ainda de acordo com Carminati (2004, p. 7), 
[e]m geral, a atividade filosófica na América Latina consiste em adotar e adequar doutrinas filosóficas europeias com o objetivo de se justificar teórica e ideologicamente as iniciativas das nossas elites, como é o caso do Positivismo, que serviu para fortalecer um processo de modernização desde o final do século passado [...] Nas últimas décadas, notadamente a partir de 1975, com a implantação de diversos cursos de pós graduação, é que esse quadro começou a se modificar.

Vimos que o positivismo também ameaçou a filosofia na França, segundo os livros de filosofia de Janet (final do século XIX). Contudo, esse mesmo positivismo serviu, no Brasil, como justificativa para a eliminação completa da filosofia dos currículos escolares, e isso já no século $X X$.

Voltemos, agora, às disciplinas que substituíram a filosofia a partir de 1971, a saber, as disciplinas de Educação Moral e Cívica (EMC) e Organização Social e Política Brasileira (OSPB). Essas duas disciplinas visavam à "defesa das tradições e manutenção da ordem e dos valores nacionais" (TOMAZETTI, 2012, p. 85) e entraram para o currículo da Educação Básica durante a reforma de 1971:

A reforma da educação básica da ditadura militar compreende a reestruturação do sistema escolar, com a criação da escola do ensino fundamental de 8 anos $\left(1^{\underline{a}}\right.$ a $8^{\underline{a}}$ séries) e a reorganização dos objetivos fundamentais do ensino de $2^{\circ}$ grau, que se volta para uma formação mais profissionalizante, como expressos na Lei 5.692/71, que "Fixa as Diretrizes e Bases do Ensino de $1^{\circ}$ e $2^{\circ}$ graus e dá outras providências". (MARTINS, 2014, p. 42).

Skidmore (1999, p. 176) descreve bem em que consistia o ensino de Educação Moral e Cívica à época:

Certain civilian allies (would-be right-wing theoreticians) of the military sought to help solidify the new regime by formulating a new compulsory educational curriculum known as "Moral and Civic Education". It consisted of an omnibus course (combining geography, geopolitics, conventionally oriented Brazilian history, and a dose of conservative civics) that was required at every level of education, public and private, from kindergarten to the doctoral level.

Em alguns livros didáticos de EMC consultados, vimos passagens que correspondem à descrição de Skidmore (1999). No livro de Bortoli (1979) - aprovado pela Comissão Nacional de Moral e Civismo, segundo informações que constam na folha de rosto -, encontramos a seguinte estrutura: capítulos intitulados "O Homem", "O Povo Brasileiro" e "O Brasil". No que concerne à "defesa das tradições" de que nos fala Tomazetti (2012), temos vários capítulos que giram em torno da tríade "família-escola-igreja", por exemplo. Uma passagem dedicada à mestiçagem do povo brasileiro ilustra a defesa dos "valores nacionais". Classificam-se os mestiços de acordo com suas misturas; assim, nas páginas 39 e 40, aprendemos os nomes específicos para as misturas mais difundidas: "branco + negro", "índio + negro" e "branco + índio". Essa mestiçagem é descrita como um valor nacional.

Já o ensino de OSPB tornou-se, de acordo com Martins (2014), obrigatório no ensino secundário (hoje Ensino Médio) em 1969, e "[c]om a Lei 5.692/71 a disciplina é mantida nos currículos escolares [...]. Já a sociologia e a filosofia, que ainda subsistiam como disciplina no $2^{\circ}$ grau, foram abolidas". (p. 45). Qual era o conteúdo da disciplina OSPB? Ainda segundo Martins (2014), 
[...] a OSPB agia, juntamente com a EMC, com uma característica muito mais prescritiva que os demais conteúdos escolares, uma vez que seus princípios eram especialmente os de promover o entendimento da ordem social e do organograma estatal. Dentre os seus conteúdos, destacam-se as definições dos três Poderes brasileiros - o Executivo, o Legislativo e o Judiciário, a organização administrativa do Estado, o conceito de participação, de comunidade, de sociedade. E embora, por vezes, seu conteúdo se confundisse com o de EMC, ela pode ser considerada uma disciplina muito mais racional e técnica, bastante pertinente para o modelo curricular que se estabeleceu durante a ditadura, que abraça o tecnicismo como matriz curricular e pedagógica. (p. 45).

O retorno da filosofia aos currículos do Ensino Médio só foi possível com muita luta, a qual já teve início nos anos 1970 (FERREIRA, 2009), durante o próprio período ditatorial. Em 1996, conseguiu-se, primeiramente, reintegrá-la como disciplina facultativa. Todavia, quando a filosofia se encontrava nessa fase de transição, não se dizia nada, nos programas, sobre a forma de integrá-la aos currículos (KOHAN, 2007), o que dificultava sua real reinserção no Ensino Médio.

É somente em 2008 que a filosofia retorna definitivamente aos currículos escolares (pela Lei Federal o 11.684/08). Desde então, a situação não parou de mudar. Em 2012, três livros didáticos integravam o PNLD (Programa Nacional do Livro Didático). Em 2015, cinco livros já compunham o mesmo programa. No entanto, a criação de um "Novo Ensino Médio" pela Medida Provisória oㅡ 746, aprovada recentemente, altera o modo pelo qual o ensino da filosofia vinha sendo concebido até então. Pretende-se, novamente, reduzir a sua importância nas grades curriculares. Como em toda situação instável, a filosofia encontrase sempre vulnerável. Ferreira (2009, p. 48) afirma que a filosofia conquistou o seu espaço nos últimos anos, mas "não sem resistência ou indiferenças por parte de outros profissionais ou setores da sociedade. Por isso, entender o contexto que traz a filosofia de volta e as suas passagens pelo ensino brasileiro desde o seu surgimento é deveras interessante". Diríamos que, mais do que interessante, essa reflexão é fundamental para que novas arbitrariedades não sejam cometidas contra o ensino da filosofia nas escolas brasileiras.

\section{Considerações finais}

Muito já foi estudado sobre a história do ensino da filosofia no Brasil, mas, pelo que nos consta, poucas são as comparações feitas com países que também integram a filosofia em seus currículos escolares. Ao longo deste artigo, procuramos mostrar como a filosofia é um ensino mais estável na França do que no Brasil. Essa tese é confirmada pela recente perda de espaço da filosofia nos currículos escolares brasileiros, com a reforma do Ensino Médio sancionada em fevereiro de 2017. Na França, cada tentativa de exclusão da filosofia dos currículos encontrou maior resistência. Embora seja importante ressaltar que a França já excluiu o ensino da filosofia dos seus currículos uma (única) vez entre 1852 e 1863, ou seja, antes que o Brasil o fizesse. Segundo os discursos dessa época, aliás, a filosofia seria uma disciplina abstrata e desnecessária. Já no Brasil, nesse mesmo período, a filosofia ainda era, curiosamente, nas palavras de Alves (2002), "presença garantida" nos currículos - e isso até o início do período republicano, em 1889.

De todo modo, tanto na França quanto no Brasil, o ensino da filosofia teve uma origem comum, tendo sido em ambos os casos implantado pelos jesuítas. Um relatório da Unesco revela que os países de tradição católica são aqueles cujo ensino da filosofia é 
mais consolidado nas escolas. (UNESCO, 2011, p. 10). Todavia, mesmo com um ponto de partida comum, a história do ensino dessa disciplina seguiu trajetórias bem distintas nos dois países.

Entre 1864 até cerca de 1950, a filosofia continuou fazendo parte dos currículos na França, ainda que tenha sofrido certa ameaça com o advento do positivismo. É mais ou menos nessa época que as duas realidades, francesa e brasileira, começam a se diferenciar. No Brasil, o período da Primeira República até o golpe de 1964 é descrito por Alves (2002) como um período de "presença indefinida" da filosofia nos currículos escolares. A própria Proclamação da República em 1889 se deu sob a influência do positivismo. Com a adoção da "hierarquia das ciências" de Auguste Comte nas reformas educacionais, a filosofia desaparece dos currículos escolares pela primeira vez no Brasil. (ALVES, 2002, p. 27). No período de 1930 até 1964, a filosofia esteve presente, mas com carga horária e espaço reduzidos nos currículos.

Por outro lado, nos anos 1950, o ensino da filosofia é questionado na França. Conforme vimos, vários filósofos de prestígio mobilizaram-se a favor desse ensino, que não foi, portanto, excluído dos currículos. Já no Brasil, com a ditadura tivemos uma ruptura definitiva. Inicia-se o período em que a filosofia passa a estar definitivamente excluída dos currículos escolares brasileiros. Desde o final da ditadura, em 1985, essa disciplina foi reconquistando seu espaço até passar a integrar a grade curricular como disciplina obrigatória em 2008.

Por fim, convém observar que a estabilidade do ensino da filosofia na França se deveu, em grande medida, ao fato de que o debate existiu. Cada "crise" da filosofia foi enfrentada ouvindo-se as partes interessadas e chegando-se a um entendimento comum, conforme vimos com o exemplo do Greph. No Brasil, a atual reforma do ensino médio se deu por uma medida provisória, não havendo um debate com professores e alunos sobre os impactos gerais dessa reforma, particularmente no âmbito do ensino da filosofia em nossas escolas.

\section{Referências}

\section{Corpus}

ARANHA, Maria Lúcia de Arruda; MARTINS, Maria Helena Pires. Filosofando: introdução à filosofia. São Paulo: Moderna, 2009.

CARDIN, Michel; HUISMAN, Denis; VERGEZ, André. Philosophie. Paris: Nathan, 2007. CHAUI, Marilena. Iniciação à filosofia. São Paulo: Ática, 2011.

COTRIM, Gilberto; FERNANDES, Mirna. Fundamentos de filosofia. São Paulo: Saraiva, 2010.

DELATTRE, Michel (Org.). Philosophie. Terminales L, ES, S. Paris: Hatier, 2012.

HANSEN-LØVE, Laurence (Org.). Philosophie. Anthologie Terminales L. ES. S. Paris: Belin, 2004.

PÉPIN, Charles. Ceci n'est pas un manuel de philosophie. Paris: Flammarion, 2010.

RUSS, Jacqueline; LEGUIL, Clotilde. Les chemins de la pensée. Philosophie Terminales 
L - ES - S. Paris: Bordas, 2012.

RUSS, Jacqueline; FARAGO, France. Nouvel abrégé de philosophie. Paris: Armand Colin, 2010.

\section{Autores citados}

ALVES, Dalton José. A filosofia no ensino médio: ambiguidades e contradições na LDB. Campinas, SP: Autores Associados, 2002.

ÁVALOS VALDIVIA, Carolina. Defensa y neoliberalización de la Filosofía: la necesidad de su derecho. Cuadernos del Pensamiento Latinoamericano, n. 23, p. 1-10, 2017. Disponível em: <http://www.cuadernoscepla.cl/web/wp-content/uploads/N23_texto_1 _Carolin_-Avalos.pdf>. Acesso em: 25 jul. 2018.

BORTOLI, Lurdes de. Educação Moral e Cívica. $2^{\circ}$ grau. São Paulo: Companhia Editora Nacional, 1979.

CARMINATI, Celso João. (Des)razões da retirada da Filosofia do Ensino Médio no Brasil. Revista Linhas, v. 5, n. 2, p. 1-13, 2004. Disponível em: <http://www.periodicos.udesc.br/ index.php/linhas/article/view/1225/1038>. Acesso em: 25 jul. 2018.

CHÂTELET, François. La philosophie des professeurs. Paris: Éditions Bernard Grasset, 1970.

. Une histoire de la raison. Entretiens avec Émile Noël. Paris: Seuil, 1992 [1979].

ENTHOVEN, Raphaël. Avant-propos. In: ENTHOVEN, Raphaël (Org.). La dissertation de philo. Paris: Fayard, 2010. p. 7-8.

FERREIRA, João Vicente Hadich. O retorno da filosofia ao Ensino Médio: reflexões e perspectivas. Cadernos UFS de Filosofia, ano 5, v. 6, 2009.

GREPH (Groupe de recherches sur l'enseignement philosophique). États généraux de la philosophie (16 et 17 juin 1979). Paris: Flammarion, 1979.

HULIN, Nicole. À propos de l'enseignement scientifique: une réforme de l'enseignement secondaire sous le Second Empire: la "bifurcation" (1852-1864). Revue d'histoire des sciences, Paris, tomo 35, n. 3, p. 217-245, jul. 1982.

JACQUIN, Robert. Hippolyte Fortoul a-t-il banni la philosophie? Revue des Sciences Religieuses, tomo 31, n. 4, p. 383-387, 1957.

JANET, Paul. Traité Élémentaire de Philosophie à l'usage des classes. Paris:

Delagrave, 1882 [1879].

KOHAN, Walter Omar. La philosophie au Brésil au fil du temps. In: GOUCHA, Moufida (Org.). La philosophie. Une école de la liberté. Paris: Organisation des Nations Unies pour l'éducation, la science et la culture, 2007. p. 78.

LE ROUX, Gaëlle. L'épreuve de "philo" au bac , une spécificité française. France 24, 2011. Disponível em: <http://www.france24.com/fr/20110615-france-enseignement-baclycee-epreuve-philosophie-specificite-francaise >. Acesso em: 25 jul. 2018.

LÖWY, Michael. Préface. In: SALLES, Severo. Dictature et lutte pour la démocratie au Brésil (1964-1985). Paris: L'Harmattan, 2005. p. 7-8.

MARTINS, Maria do Carmo. Reflexos reformistas: o ensino das humanidades na ditadura militar brasileira e as formas duvidosas de esquecer. Educar em Revista, Editora UFPR, n. 51, p. 37-50, jan./mar. 2014. 
MOIRAND, Sophie. Des choix méthodologiques pour une linguistique de discours comparative. Langages, n. 105, p. 28-41, 1992.

PINTO, Louis. La vocation et le métier de philosophe. Paris: Seuil, 2007.

Les philosophes entre le lycée et l'avant-garde. La métamorphose de la philosophie dans la France d'aujourd'hui. Paris: L'Harmattan, 1987.

POUCET, Bruno. Enseigner la philosophie. Histoire d'une discipline scolaire. 18601990. Paris: CNRS Éditions, 1999.

POWELL, Jason. Jacques Derrida: a biography. New York: Continuum International Publishing Group, 2006.

RODRIGUES, Zita Ana Lago. O ensino da Filosofia no Brasil no contexto das políticas educacionais contemporâneas em suas determinações legais e paradigmáticas. Educar em Revista, Curitiba, Editora UFPR, n. 46, p. 69-82, out./dez. 2012.

SALLES, Severo. Dictature et lutte pour la démocratie au Brésil (1964-1985). Paris: L'Harmattan, 2005.

SARDÁ, Daniela Nienkötter. Les manuels de philosophie en France et au Brésil: une analyse du discours contrastive de la prise en charge énonciative. 2015. Tese (Doutorado em Ciências da Linguagem) - Université Paris Descartes, 2015. Disponível em: <https://tel.archives-ouvertes.fr/tel-01237282>. Acesso em: 25 jul. 2018.

SHERRINGHAM, Mark. L'enseignement scolaire de la philosophie en France. La revue de l'inspection générale, Paris, n. 3, 2006. Disponível em:

<http://media.education.gouv.fr/file/38/6/3386.pdf>. Acesso em: 25 jul. 2018.

SKIDMORE, Thomas E. Brazil. Five Centuries of Change. New York: Oxford University Press, 1999.

TELES, Edson; SAFATLE, Vladimir. Apresentação. In: TELES, Edson. O que resta da ditadura: a exceção brasileira. São Paulo: Boitempo, 2010. p. 9-14.

TOMAZETTI, Elisete T. Produção discursiva sobre ensino e aprendizagem filosófica.

Educar em Revista, Curitiba, Editora UFPR, n. 46, p. 83-98, out./dez. 2012.

TROGER, Vincent. Du latin à la terminale $S$, l'héritage élitiste des lycées. Regards sur l'actualité, Paris, n. 353, 2009. Disponível em:

$<$ http://www.inegalites.fr/IMG/pdf/Regards_353_Vincent_Troger.pdf>. Acesso em: 25 jul. 2018.

UNESCO (Organização das Nações Unidas para a educação, a ciência e a cultura). L'enseignement de la philosophie en Europe et Amérique du Nord. Paris, 2011. 
DANIELA NIENKÖTTER SARDÁ é pós-doutoranda na Universidade de São Paulo (USP) e doutora em Ciências da Linguagem pela Université Paris Descartes/Sorbonne Paris Cité.

Endereço: Av. Prof. Luciano Gualberto, 403, 05508-900, Cidade Universitária, São Paulo/SP, Brasil.

E-mail: danielasarda@gmail.com

Recebido em 15 de agosto de 2017.

Aceito em 30 de julho de 2018. 